\title{
Material Conditions of Collaborative Knowledge Construction: The Case of Monoplant
}

\author{
Anders I. Mørch ${ }^{1}$, Hani Murad ${ }^{2}$, Jo Herstad ${ }^{2}$, Sjur Seibt $^{2}$, and Morten Kjelling ${ }^{2}$ \\ Dept. of Education ${ }^{1}$ and Dept. of Informatics ${ }^{2}$, University of Oslo, Norway
}

\begin{abstract}
Monoplant is a prototype of an educational construction kit that provides teachers and secondary school students with hands-on experience on plant biology. We present the design rationale of Monoplant and report on its three-week deployment in a high school classroom. The students $(\mathrm{N}=14)$ used Monoplant to solve a photosynthesis assignment requiring them to compare the growth of two plants (one exposed to natural light and another to artificial green light). We used a qualitative approach to collect and analyze data, with observation, video recording, and interaction analysis as the main methods. The students worked in groups, and we video-recorded the verbal and non-verbal interactions of one group $(\mathrm{N}=4)$. The two plants and Monoplant's visualizations of the plants' growth, together with the textbook, were the resources that the students used when solving the assignment. These material conditions provided an explorative design space for the students' collaborative learning, and many hypotheses were raised during the hands-on activity with materials and representations. Furthermore, we suggest an emergent practice based on our findings, which are teachers' maker spaces for creating material conditions for students' domain-specific collaborative knowledge construction.
\end{abstract}

\section{INTRODUCTION}

With the advent of the Internet of things, sensors have become available in many different forms and packages. Almost as flexible as Lego bricks, sensors are relatively inexpensive and can be used as building blocks in different applications. To explore this infrastructure for educational purposes, two of the authors designed and built Monoplant for teaching and learning plant biology. With Monoplant, plants in pots are connected to sensors that measure temperature, humidity, light level, and soil moisture. Monoplant supports students' hands-on interaction with plants and provides visualizations of the key environmental variables contributing to plant growth. In this way, the causal relationships that are important for understanding scientific concepts, such as photosynthesis, can be represented in meaningful ways. By interacting with Monoplant, students are stimulated to discuss, analyze, and reason with observed (biological) phenomena and (visual and numeric) representations to create alternative explanations, which is a step beyond learning from conventional textbooks (text and static diagrams). Thus we provide support of both physical and conceptual dimensions of learning.

The rest of the chapter is organized as follows. We argue that collaborative knowledge construction in computer-supported collaborative learning (CSCL) needs a better material foundation that supports hands-on activities. We present the design rationale of Monoplant for addressing the challenge, as well as the research questions guiding our research. Then, our methods are described. Next, we present and analyze the data by showing concrete examples, and we discuss our findings by comparing them with those reported in related work. Finally, we present emergent practices based on our work (construction kits for teachers, teachers as designers). 


\section{RELATED WORK AND THEORETICAL PERSPECTIVES}

We describe some related work in the areas of material conditions for learning, tangible interfaces, and CSCL.

The material conditions of learning from a sociocultural perspective are associated with the tools used during learning and learners' use of spontaneous (everyday) concepts before they can master scientific concepts (Vygotsky, 1978). A good teacher will make the students rise to higher levels by bringing their spontaneous concepts in contact with scientific concepts. As a result, the students will have the experience and related concepts necessary to construct scientific concepts. We argue that the use of Monoplant creates real-life experiences for students and triggers spontaneous concepts that become prerequisites for the scientific understanding of photosynthesis.

Säljö (2010) conducted early studies on the use of computer tools as mediating artifacts for teaching and learning practices. These tools do not only support learning but may also transform it. One role of computer tools in learning, according to Säljö, is to serve as a social memory: in addition to memorizing knowledge, we maintain a knowledge base connected with the tools we use (Säljö, 2010).

Johri and Olds (2011) suggested the following three areas for future research on the social and material contexts for learning in engineering: 1) empirical studies on the role of representations, 2) empirical studies on mediation by the tools used in learning and practice, and 3) empirical studies on the differences between the use of representations and materials in learning. We address each of these in the study we report in this chapter.

Marshall (2007) surveyed previous research on tangible interfaces to identify the benefits of technological artifact manipulation on learning. He found only a few studies that focused explicitly on the teaching and learning benefits of artifact manipulation and classified them into explorative activity and expressive activity. Both types apply in our case.

Within the past 10 years, technological innovations in society have created new opportunities for handheld technology in schools (Jahnke, 2015), and educational construction kits (a type of maker space) offer new ways of increasing engagement in learning through hands-on activities (Bdeir, 2009). Advocates say that these help motivate learning by encouraging active participation in science and technology topics (Resnick et al., 1998), and argue that physical interactions lead to a better learning transfer beyond classroom settings because of the improved grounding of students' learning in out-of-school experiences (Black et al. 2012).

By contrast, critics speak of hands-on activities being at odds with educational practice and increasing the tension between learner-centered (self-driven) and teachercentered (curriculum driven) learning (Resnick, 1987; Barricelli et al., 2016). Selfdriven learning is connected with constructivism and entails that a learner's prior experience must be the starting point for new learning activities and further guided by personal learning goals. Curriculum-driven learning starts from shared learning goals often defined nationwide for specific subjects to ensure that all students have a common core knowledge base. We attempt to strike a balance between self-driven and curriculum-driven learning with Monoplant by integrating students' hands-on 
activities with materials and representations and by giving students an assignment informed by the high school biology curriculum for grade 12 .

Jimenez-Aleixandre, Rodriguez, and Duschl (2000) made a distinction between two types of classroom discourses - doing science and doing the lesson. Doing science is when students are talking science in the classroom (Lemke, 1990), and doing the lesson is when they are displaying the roles of students and the rules to follow when solving a task.

Collaborative knowledge construction is a pedagogical model that promotes talking science by raising questions or issues, followed by alternative answers (hypotheses, positions, or alternative explanations) and backed up by arguments either for or against a position on an issue (Scardamalia \& Bereiter, 2003; Stahl, 2006). This learning model allows the progression of scientific inquiry from a vague problem or poorly formulated question toward a clarification of the phenomenon being studied.

CSCL researchers have put technological manipulation and materiality in the background and foregrounded argumentative (discursive) learning processes, but studies have shown that active engagement with materials, representations, and artifacts can significantly enhance CSCL (Cerratto-Pargman, Knutsson, \& Karlström, 2015). Furthermore, teachers can use variations of collaborative knowledge construction for inductive learning methods, such as problem-based learning, discovery learning, and project-based learning (Prince \& Felder, 2006). By putting materiality and representations in the foreground, researchers can begin to unravel the complex relationship between learning and technology inherent in socio-cultural mediation (Cerratto-Pargman, Knutsson, \& Karlström, 2015).

\section{THE MONOPLANT SYSTEM}

Two of the authors created Monoplant from basic hardware and software components as a part of their master's thesis (Seibt \& Kjelling, 2014), and it took about two years to build it. The hardware consists of five sensors that measure, record, and store data variations in the plant's growth environment, an Arduino prototyping platform connecting the low-level electronic sensors to higher-level electronics (Arduino, 2017), and a Raspberry Pi programmable computer (Raspberry, 2017). The hardware system (Figure 1) consists of a wireless network adapter, a high-definition webcam, a powered USB hub, and the Arduino to the Raspberry Pi (2012 model). Arduino and Raspberry were chosen because they are open source hardware and software platforms and provide for flexibility in adaptation. Monoplant has not been commercialized and remains a prototype. Teachers were not involved in the technological design, but a teacher was involved in the pedagogical design we describe in the Methods section.

The data collected by the sensors are posted to an application programmer's interface (API) and stored in a common repository (cloud). The API provides an interface between the data collector and the user interface. The software consists of an architectural style for distributed hypermedia systems (Fielding, 2000). It uses Ruby on Rails, an open-source web application framework with the Ruby object-oriented programming language. Furthermore, time-lapse video software, which enables observing the details and nuances of a growing plant because time-lapse photography 
utilizes snapshots taken at fixed intervals, as well as HTML5 and JavaScript, is used to display the data collected by Monoplant.

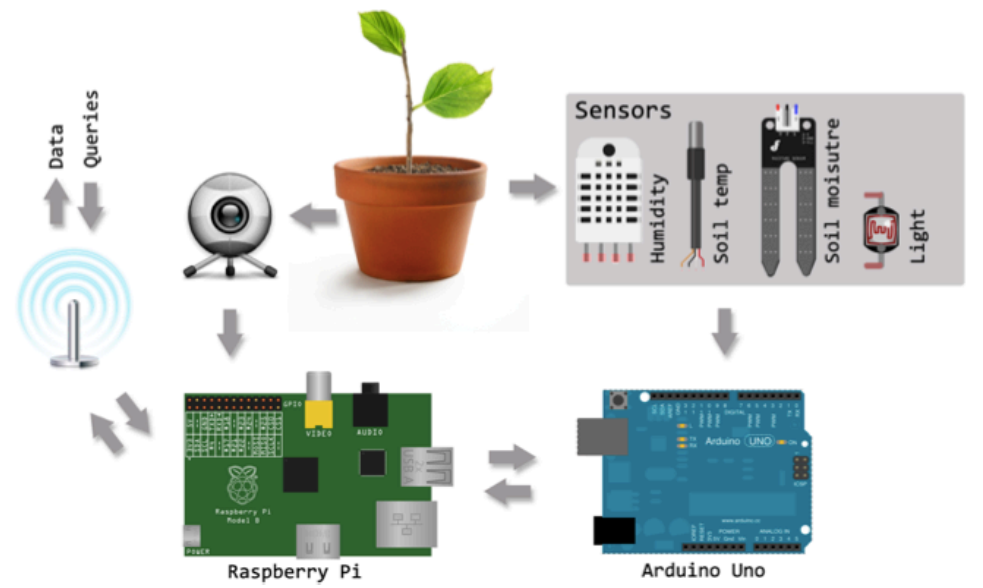

Figure 1. High-level illustration of the hardware components in the application

Each day at midnight, the system collects all the images taken during the day and combines them into a time-lapse video played back at 30 frames per second. As the Raspberry Pi captures approximately one picture per minute, two seconds in the video equals one hour in real life, and one day is represented by a time-lapse video of 48 seconds. Thus, after 24 hours of data collection and storage, videos in different formats are generated, and Monoplant is ready to display information to users (Seibt \& Kjelling, 2014).

The main web page of each plant represents the current state of the plant (Figure 2). The pane on the upper left side of Figure 2 displays the last picture with the corresponding values for temperature, humidity, light, and soil moisture. The large pane on the upper right side shows a time-lapse video from the day before, with a corresponding graph showing all the sensor values throughout that day.

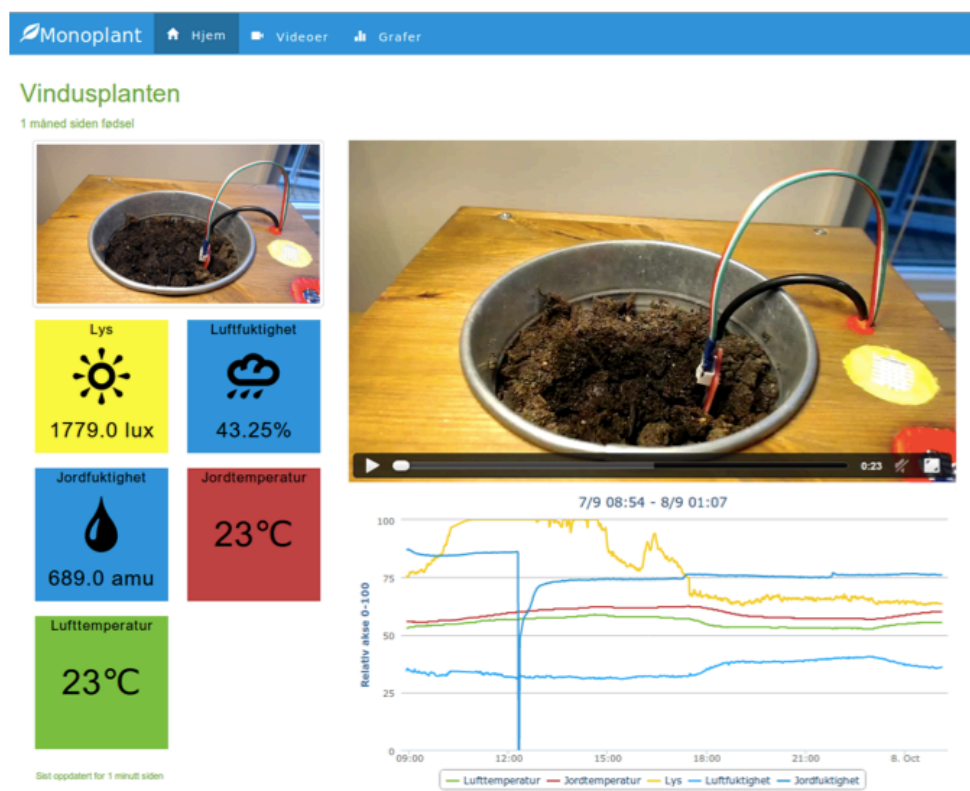

Figure 2. Monoplant's user interface displays the values of the plant's physical variables and growth behavior by static and dynamic visualizations (snapshot, current attributes, video, and graph) 


\section{PHOTOSYNTHESIS}

Photosynthesis is the biological process and scientific concept that was the topic for teaching in the class we observed (Sletbakk et al., 2008). It is the process by which green plants use chlorophyll in their leaves to transform energy from light to chemical energy, often in the form of glucose, which is used by the plant to build seeds, leaves, and flowers. Oxygen is produced as a by-product of the plant biochemical process, and it enables humans and all other animals to breathe. Photosynthesis occurs more in blue and red light rays than in green light rays (Nishio, 2000).

\section{RESEARCH QUESTIONS}

The overall aim was to provide an understanding of students' manipulation of physical materials and representational artifacts in Monoplant, while collaborating in small groups to learn about photosynthesis with some guidance from two facilitators. The following two research questions were explored:

1. What material conditions of collaborative knowledge construction does Monoplant bring to the foreground?

2. How does Monoplant, by presenting photosynthesis differently from established educational practices, reflect tensions between curriculum- and self-driven learning?

\section{METHODS}

Data collection took place in an upper secondary school in Oslo. We contacted the school half a year before the trial and asked if a biology teacher would be willing to use Monoplant in one of his classes instead of performing the textbook experiment about photosynthesis. Our interventionist approach combines participatory design (Simonsen \& Roberson, 2013) and design-based research (Hoadley, 2002), in which a teacher and two researchers collaborated to design and deploy an innovation while conducting an experimental study of the innovation. The biology class consisted of eleven girls and three boys $(\mathrm{N}=14)$ aged $17-18$ years (on their last year in high school).

We used qualitative methods for data collection, classification, and analysis. First, we observed and video-recorded spoken interactions intertwined with physical actions by four of the students. Second, data classification used thematic analysis and was informed by research questions, argumentation models (Scardamalia \& Bereiter, 2003; Stahl, 2006), and the assignment questions. Third, interaction analysis (Jordan $\&$ Henderson, 1995) was used as our main method for analysis. Interaction analysis is a method for the empirical investigation of human activities, such as talk, nonverbal interaction, and the use of artifacts and technologies (Jordan \& Henderson, 1995). The transcript notation is shown in Table 1.

Table 1: Transcript notation for conversational data

\begin{tabular}{|c|c|}
\hline Notation & Indicating \\
\hline$[.]$. & Excluded speech from person speaking \\
\hline$(($ text $))$ & Comments/explanation by researcher \\
\hline text.... & Speech fading out \\
\hline [text[ & Talk on top of each other \\
\hline & Short pause in talk $0-0.5$ seconds \\
\hline (number) & Short pause in talk, time of pause in sec. \\
\hline$::$ & Abruption of talk \\
\hline courier & Written (e.g. GUI) text read out loud \\
\hline$\{\{$ move $n\}\}$ & Physical action / movement by person \\
\hline
\end{tabular}




\section{Experimental set-up}

After a demonstration of the system to the teacher, followed by a discussion of its functionality, the teacher suggested that we conduct two experiments using the different sensors in the system to control the change in one variable while keeping the others relatively stable. We agreed that the factors that would be easiest to control are light intensity and light quality (wavelength). The first experiment would involve keeping the plant located in a window facing west, receiving sunlight and light from fluorescent indoor lighting. In the second experiment, the plant would be relocated to a lightproof cabinet where it would only receive light of a known wavelength, and it would be compared with another plant located in the window (Figure 3).

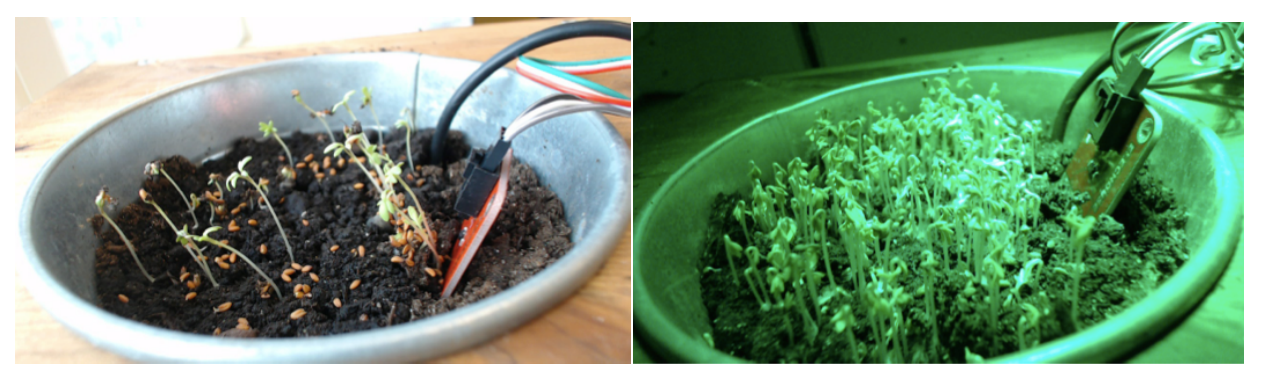

Figure 3. Left: plant A receiving natural light in the window; right: plant B receiving green light in the cabinet

The students had access to Monoplant for 3 weeks and used it for preparatory work. When the assignment was handed out, the students were seated in groups and were asked to collaborate. We reported on a 45-minute session of one group of four students and go into the depth of their conversation during the first 17.5 minutes. The assignment consisted of five questions about photosynthesis covered in class and adapted to the unique setting, which included comparing two conditions for exposing plants to light (Figure 3).

\section{RESULTS}

\section{Overview of the findings}

The plants in the cabinet grew more than the plants exposed to sunlight, which, on the basis of first impression, is contrary to common sense. The experimental set-up encouraged the students to question their previous (textbook) understanding of a scientific process, develop new knowledge, and integrate their skills into a real-life context. Table 2 shows the number of utterances and hypotheses (personal explanations, tentative answers) generated by the observed group and captured on video.

Table 2: Number of utterances and hypotheses generated by the students

\begin{tabular}{llllll}
\hline \hline No./student & Linda & Nora & Siri & Fredrik & All \\
\hline Utterances & 14 & 118 & 182 & 67 & 381 \\
Hypotheses & 0 & 3 & 8 & 4 & 15 \\
\hline
\end{tabular}

Monoplant mediated the students' actions but not their conversations, which were mediated by the assignment, group organization, and the teacher's scaffolding. During thematic coding, we identified the following types of utterances: 1) asking questions, 
2) proposing hypotheses, and 3) arguing for and against the different hypotheses by 3a) referring to observations and $3 \mathrm{~b}$ ) pages in the textbook. We identified 15 hypotheses proposed by the four students during the 45-minute session. The hypotheses were named and chosen by the authors and assessed to be representative of the data. During hypothesis generation and argumentation, the students made frequent references not only to visual representations obtained from Monoplant, such as, for instance, graphs and time-lapse videos (see Figure 2), but also to the actual plants (see Figure 3) and the textbook (Sletbakk et al., 2008). These actions and interactions were the focus for our analysis.

We present and analyze four hypotheses: green light, stem color of the plant, energy source in the seed, and delayed leaf budding. Each subsection starts with a brief context description, followed by the excerpt in verbatim transcription, and then our analysis.

\section{Hypothesis 1: Green light}

The students were divided into groups of four. The group we followed has read the assignment and noticed the differences of the two conditions. Siri read the first question aloud: "What did you expect would happen?" The students have rehearsed some of the theories presented in class (e.g., soil moisture decreasing over time). The students appeared slightly nervous at first, but as we proceeded, they became more relaxed and motivated, and the discussion shifted from making general observations to generating personal explanations, as shown below:

\section{Time Who Utterance \\ 2:16 Siri ... It was when the plant was put in $\{\{$ points to cabinet $\}$ the cabinet; it should have been exposed only to green light ... but it is possible, for example, that a small amount of other light could have entered the cabinet, as well ... so it's not for sure that the plant was exposed only to green light ... \\ $2: 31 \quad$ Nora $\quad\{\{$ Nods $\}\}$}

Siri promptly starts with a conjecture about the plant in the cabinet (plant B). She proposes that the plant received more green light, indicating that there could be an error in the experiment. Nora agrees with this by slightly nodding. Siri implies that the plant in the cabinet will not grow as tall as plant $\mathrm{A}$ in the window.

The student textbook (Sletbakk et al., 2008) contains a graphical model of photosynthesis that shows how solar energy is used to excite electrons in chlorophyll molecules, but the students are not able to connect the model with plant B's growth pattern. The book also contains a graph of different pigments according to the wavelengths of light they absorb, clearly showing that chlorophyll absorbs little green light. The teacher used this as a discussion point in earlier lectures; he asked why the plants' leaves appear green.

\section{Hypothesis 2: Stem color of the plant}

The group, as a whole, does not share the hypothesis of Siri supported by Nora, but it is not discarded. The students start to search for alternative explanations, which is triggered by a surprise observation of Siri:

\section{Time Who Utterance}

2:47 Siri Or almost all green light at best ... \{\{pointing toward the desk $\}$, but how much did it actually grow? Is it that one \{\{pointing to plant $B$ sitting on the 
desk\}\} that was previously in the cabinet?

2:53 Nora Wow(!) ((Becomes surprised to learn that plant B has grown more than plant $A)$ )

2:53 Siri It has grown a lot ((smiles)).

2:59 Siri But were the stems of the $\{$ points to the window $\}$ plant in the window also white? ((Referring to the observation on plant B's white stem color $))$.

Siri is surprised to find plant B being taller and more plentiful than plant A. The first hypothesis has now been contested by one contradictory observation and a new hypothesis: 1) plant B grew more than plant A, and 2) plant B has a white stem color.

The second observation leads Siri to asking, "But were the stems of the plant in the window also white?" This question is very appropriate because a plant that does not absolutely undergo photosynthesis would most likely be white, as a result of having no pigments. The reason she asked this might be related to a comment made by a classmate in a previous lecture that when plants were placed in the basement for winter storage, their leaves would turn white.

\section{Hypothesis 3: Energy source in the seed}

The teacher joins the group 11 minutes later and asks the students to explain why plant B grew more than plant A. Siri repeated her green light hypothesis (Hypothesis 1). At this point, they enter the following conversation:

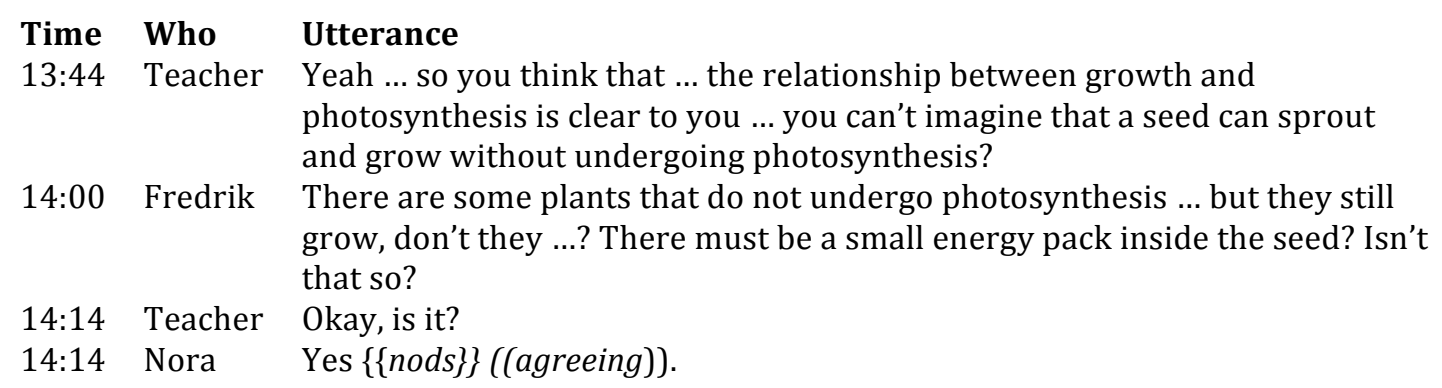

The teacher raises a question that challenges Siri's first hypothesis, making the group to think that light is not the only source of growth. By using the words "seed" and "sprout," the teacher hints at germination (Sletbakk et al., 2008). Fredrik proposes the hypothesis that some plants grow without photosynthesis and use an "energy pack inside the seed." The teacher asks them to elaborate. Nora agrees with this, but we do not yet know if this is a shared understanding in the group.

\section{Hypothesis 4: Delayed leaf budding}

The teacher just left the group. One of the researchers asked the students to watch the videos of each of the conditions to see if any discrepancy exists in the sequence of leaf appearance in the two plants. The students observed plant B and found that it is mainly the stem that grows, not the leaves. Fredrik requests that they also check plant A for comparison, and Siri starts the video from October 29 showing plant A's growth process. The following conversation takes place:

\begin{tabular}{|c|c|c|}
\hline Time & Who & Utterance \\
\hline $17: 12$ & Siri & $\begin{array}{l}\text { See, the leaves open up almost immediately }\{\{\text { Nora looks at the video of } \\
\text { plant } A \text { ((and compares it })) \text { with plant } B \text { that was put on the desk }\} \text {. }\end{array}$ \\
\hline $17: 15$ & Fredrik & $\begin{array}{l}\text { Yes ... (( silence, waiting for the video to finish })) \text {; it could be that it needs the } \\
\text { leaves }\{\{\text { places one hand over the desk, then moves it quickly up in the air, as } \\
\text { if trvina to canture somethina fallina in the air }\}\} \text { to canture light but }\{\{\text { nods }\end{array}$ \\
\hline
\end{tabular}




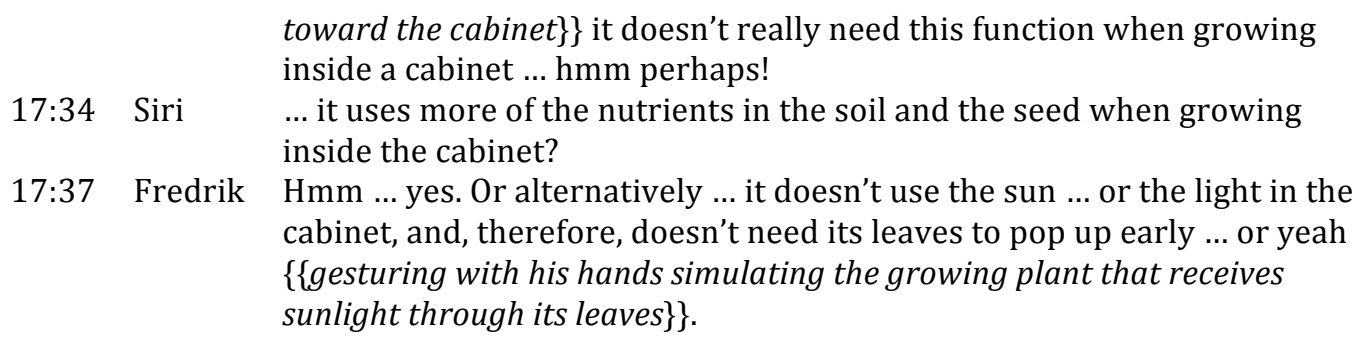

Siri mentions that the leaves of plant A open almost immediately. Fredrik agrees, waits for the video to pause, and then says that plant A uses its leaves to capture light, whereas plant $\mathrm{B}$ does not need this function. Siri clarifies in a questioning tone if Fredrik meant that plant B compensates by using more nutrients from the soil and the seed to grow. Fredrik agrees somewhat hesitantly but suggests an alternative (delayed leaf budding) hypothesis that plant B's leaves pop out late because there is no sunlight to capture. Siri and Fredrik are both partly right but are unwilling to agree on the same hypothesis or to synthesize their hypotheses into a common understanding. Perhaps, they still want to hold on to their own hypothesis until further evidence will confirm or refute it.

The textbook explanation of the phenomenon is that photosynthesis occurs in the leaves. Different pigments in the chlorophyll can absorb photons, which can excite electrons and then trigger other photosynthesis subprocesses. Plants, therefore, need leaves to perform photosynthesis. However, the book does not say anything about growth without photosynthesis, such as in locations of little light and for whitecolored plants, the scenario that the students are faced with in this experiment. Thus, the students are discussing a complex phenomenon that is not fully explained in the textbook and that requires them to use their own vocabulary and propose alternative hypotheses obtained from multiple sources, their teacher's feedback, and unsatisfactory previous hypotheses. However, the group is not able to converge on a common solution.

We show in the next section that by stimulating interactions with materials and representations (in addition to verbal interactions in the group), Monoplant provides a rich set of material conditions for collaborative learning through the exploration of alternative answers. Following others (e.g., Cerratto-Pargman, Knutsson, \& Karlström, 2015), we argue that such a broad (physical-conceptual) learning environment is necessary for a deeper understanding of the complex relationship of learning and technology mediation.

\section{GENERAL DISCUSSION}

We summarize our findings by discussing our research questions raised in the beginning of the chapter and comparing our results with some of the results and recommendations reported in the literature surveyed.

\section{What material conditions of collaborative knowledge construction does Monoplant bring to the foreground?}

Monoplant gives students access to two types of materials: physical materials (plants, pots, etc.) and visual representations (videos, images, etc.). The students engaged with all of the materials but to varying degrees, and some students were more active than others. Our study provides an example of empirical research on mediation by physical 
tools used in learning and combining representations and materials during the learning process (Johri \& Olds, 2011). However, our data do not allow us to differentiate the relative importance of physical materials, textbook illustrations, and computational representations on collaborative learning, because we did not distinguish the different types of materials in the experimental set-up. This shortcoming indicates an area for further research.

The students used materials in both explorative and expressive learning activities (Marshall, 2007). They were exploring alternative answers (generating hypotheses) when solving the assignment, and the multiple representations and interactions with the plants aided exploration. The students were expressing personal learning goals by choosing to interact with a certain representation, thus revealing interest and favoring a specific hypothesis, which, perhaps, can be connected with personal experiences and prior knowledge. However, this behavior cannot be determined with certainty on the basis of our research methods, and it was partly prompted by the teacher and the two research assistants, as they occasionally interacted with the students to scaffold the learning activity.

We found preliminary evidence of multiple levels of interaction with materials and representations when proposing a new hypothesis: 1) students would choose among different representations, such as a static picture, a textbook diagram, a video snippet, and visible plant properties, among others, when proposing a new hypothesis; 2) when two hypotheses were proposed, they were compared, contested, and (if not rejected) integrated to form a better one (this did not occur during the first 17.5 minutes, but occurred later in the 45-minute session; for instance, Siri and Fredrik proposed competing hypotheses that were each partly correct and were eventually combined); and 3) if a hypothesis was found to be incompatible with later observation and scrutiny, it would be replaced with a better one (e.g., Siri's green light hypothesis was later replaced with a stronger one by Fredrik and supported by Siri, as she gradually adopted a scientific attitude). These three levels of interacting with materials and representations during collaborative learning with Monoplant are tentative findings and require further investigation.

\section{How does Monoplant, by presenting photosynthesis differently from established educational practices, reflect tensions between curriculum- and self-driven learning?}

The tension between self-directed and curriculum-driven learning is manifest in several respects. Self-directed learning means that students pursue individual trajectories (based on prior knowledge and experiences) using preferred methods and directed toward personal learning goals (e.g. different interpretations of assignment) and is exemplified by Fredrik and Siri proposing and arguing for different hypotheses.

However, during our observations, the students were evidently interested mostly in learning the curriculum and in memorizing correct answers to the assignment questions anticipated to be in an upcoming test and in the final exam. The students therefore seemed focused on what was expected of them based on established educational practices. In other words, they were primarily interested in "doing school" (Jimenez-Aleixandre, Rodriguez, \& Duschl, 2000).

By engaging in collaborative knowledge construction while interacting with 
Monoplant, the students were doing science (Jimenez-Aleixandre, Rodriguez, \& Duschl, 2000) but were doing so by using everyday language to explain what is happening. The students' talk during their scientific inquiry could have been lifted a notch by the teacher if he reminded them more often to use scientific concepts in explaining the observed data, thus integrating the hands-on activity with the desired student behavior. For example, when the teacher interacted with the students in hypothesis 3 , they were prompted to reflect on how the plant can grow without photosynthesis, but he did not lead them to using scientific concepts to more accurately verbalize their understanding.

In other words, the students are capable of navigating both types of representations separately and can manage multiple representations of the same kind (for example, in hypothesis, 4 the students discuss content from a video while pointing to one of the plants), but they are not able to connect representations across the two domains. Therefore, we did not find evidence of the direct application of scientific concepts when the students were left to discuss on their own. It only occurred when the teacher triggered the students to use scientific concepts. The students seem to suppress their curiosity when doing schoolwork and not referencing scientific models when doing science with Monoplant. Some changes in institutional practice might be necessary before the personal experiences created with Monoplant and related maker spaces can function as anchors for learning scientific concepts, perhaps along the lines suggested by Vygotsky with the notion of using spontaneous concepts as building blocks of scientific concepts (Vygotsky, 1978). This hypothesis is currently a tentative one based on our findings. Further research is needed to determine what kinds of institutional practices should be introduced to high school students in our case. We suggest one approach in the final section.

\section{CONCLUSIONS AND DIRECTIONS FOR FURTHER WORK}

The overall aim of the study reported in this chapter is to understand students' handson activity with physical materials and representational artifacts of Monoplant while collaborating in small groups to solve an assignment on photosynthesis. Two of the authors designed and developed Monoplant from basic hardware and software components (Seibt \& Kjelling, 2014). It consists of a biological plant with five sensors attached, a cloud solution for storing data, and a user interface on a web page that displays a range of dynamic and static visualizations of a plant's growth process.

Monoplant was deployed in a high school classroom for three weeks. The students interacted with Monoplant to solve an assignment in groups of four. We used a qualitative approach to collect and analyze data, with observation, video recording, and interaction analysis as the main methods. We video-recorded all spoken utterances and turn taking in one of the groups, with a focus on the students' conversations interspersed with physical actions toward the plants, Monoplant, and the textbook to access information for help in answering the assignment.

The students proposed alternative answers to the assignment questions based on the different materials and the representation they had access to. The learning environment thus promoted both self-directed learning through personal learning trajectories (by following a chosen hypothesis toward a conclusion) and curriculumdriven learning through the assignment that was created together with the teacher. 
We also found that the textbook's and the teacher's presentation of photosynthesis provided students with scientific vocabulary, and Monoplant provided them real-life (physical) experiences related to the assignment. The students had difficulty connecting the two forms of representations (textbook/lectures and Monoplant/plants), and the teacher became central for scaffolding by enabling the students to move from concrete experiences with Monoplant (spontaneous concepts) to the more abstract language used in the textbook (scientific concepts). But this was realized only in a few instances, as the teacher also attended to other groups.

Directions for further work include but are not limited to the following:

- The basic building blocks of Monoplant (see Figure 1) offer a maker space for two researchers to create Monoplant. Now, imagine a meta-design environment for teachers to accomplish the same using end-user development (e.g., Fischer, 2009; Mørch et al., 2014). What should be the level of abstraction of its building blocks? Should it be low level and general (like we used for building Monoplant) and enable a wide range of learning environments in science and technology topics, or should it be high level and domain specific, which is easier to use for non-techies but with a narrower range of application?

- We propose the comparison of the relative strengths and weaknesses of different types of materials (biological and physical) and representations (digital and textual) to complement collaborative learning as a verbal activity

- We also propose three levels of interactions with materials and representations during collaborative learning with Monoplant, which are tentative and require additional research for harnessing, including reusing, refuting, and adapting the three levels.

\section{References}

Arduino (2017). Open-source Electronics Prototyping Platform. Retrieved from http://www.arduino.cc

Barricelli, B.R., Fischer, G., Fogli, D., Mørch, A., Piccinno, A., \& Valtolina, S. (2016). Cultures of Participation in the Digital Age: From "Have to" to "Want to" Participate. In Proc. NordiCHI'16. ACM, New York, USA, Article 128, 3 pages.

Bdeir, A. (2009). Electronics as material: littleBits. In Proceedings of the 3rd International Conference on Tangible and Embedded Interaction (TEI '09). ACM, New York, NY, USA, 397-400.

Black, J.B., Segal, A., Vitale, J., \& Fadjo, C.L. (2012). Embodied cognition and learning environment design. In: D. Jonassen \& S. Land (Eds.), Theoretical foundations of learning environments, Routledge, New York.

Cerratto-Pargman, T., Knutsson, O., \& Karlström, P. (2015). Materiality of online students' peer-review activities in higher education. In Proceedings of CSCL 2015. Exploring the material conditions of learning: Opportunities and challenges for CSCL. Gothenburg. ICLS Press. pp. 308-315.

Fielding, R. T. (2000), Architectural styles and the design of network-based software architectures, $\mathrm{PhD}$ thesis, Dept. of Information and Computer Science, University of California, Irvine. 
Fischer, G. (2009). End-user development and meta-design: Foundations for cultures of participation. In Proceedings IS-EUD 2009 (pp. 3-14). Berlin-Heidelberg: Springer.

Hoadley, C. (2002). Creating context: Design-based research in creating and understanding CSCL. In G. Stahl (Ed.), Proc. CSCL 2002 (pp. 453-462). Mahwah, NJ: Lawrence Erlbaum Associates.

Jahnke, I. (2015). Digital Didactical Designs: Teaching and Learning in CrossActionSpaces. Routledge, New York, NY.

Jimenez-Aleixandre, M., Rodriguez, A., \& Duschl, R. (2000). "Doing the Lesson" or "Doing Science": Argument in high school genetic. Science Education, 84, 757-792.

Johri, A., \& Olds, B. M. (2011). Situated engineering learning: Bridging engineering education research and the learning sciences. Journal of Engineering Education, 100 (1), 151-185.

Jordan, B. and Henderson, A. (1995). Interaction analysis: Foundations and practice. The Journal of the Learning Sciences, 4, 39-103.

Lemke, J. (1990). Talking science: Language, learning, and values. Norwood, NJ: Ablex.

Ludvigsen, S.R. and Mørch, A.I. (2010). Computer-supported collaborative learning: Basic concepts, multiple perspectives, and emerging trends. In P. Peterson and B. McGaw (Eds.), International Encyclopedia of Education (pp. 290-296). Elsevier, Oxford, UK.

Marshall, P. (2007). Do tangible interfaces enhance learning?. In Proceedings of the 1st international conference on Tangible and embedded interaction (TEI'07). ACM, New York, NY, USA, 163-170.

Murad, H., Mørch, A.I., Herstad, J., Seibt, A. \& Kjelling, M.O. (2015). Monoplant: Developing an Innovative CSCL Application for Teaching Photosynthesis Using Multiple Representations. Proc. CSCL 2015, pp. 817-818.

Mørch, A.I., Hartley, M.D., Ludlow, B.L., Caruso, V., \& Thomassen, I. (2014). The Teacher as Designer: Preparations for Teaching in a Second Life Distance Education Course, 2014 IEEE 14th International Conference on Advanced Learning Technologies, Athens, 2014, pp. 691-693.

Nishio, J.N. (2000). Why are higher plants green? Evolution of the higher plant photosynthetic pigment complement. Plant Cell Environ., 23, 953-961.

Prince, M.J, \& Felder, R.M. (2006). Inductive Teaching and Learning Methods: Definitions, Comparisons, and Research Bases. Journal of Engineering Education, 95, 123-138. 
Resnick, L.B. (1987). Constructing knowledge in school. In L. S. Liben (Ed.), The Jean Piaget Symposium series. Development and learning: Conflict or congruence? (pp. 19-50). Hillsdale, NJ: Lawrence Erlbaum Associates.

Resnick, M., Martin, F., Berg, R., Borovoy, R., Colella, V., Kramer, K., \& Silverman, B. (1998). Digital manipulatives: New toys to think with. In: Proceedings of CHI'98, pp. 281-287.

Säljö, R. (2010). Digital tools and challenges to institutional traditions of learning: Technologies, social memory and the performative nature of learning. Journal of Computer Assisted Learning, 26(1), 53-64.

Scardamalia, M., \& Bereiter, C. (2003). Knowledge Building. In Encyclopedia of Education, 2nd ed. (pp.1370-1373). New York: Macmillan Reference, USA.

Seibt, M., \& Kjelling, M. (2014). Problems and Opportunities in Students' Scientific Inquiry with Monoplant. M.S. thesis, Dept. of Informatics, University of Oslo.

Simonsen, J., and Robertson, T. (eds.) (2013). Handbook of Participatory Design, Routledge, London.

Sletbakk, M., Gjærevoll, I., Håpnes, A., Hessen, D., Røsok, Ø., Borge, O., \& Heskestad, P. BIOS Biologi 2. Oslo, Norway: Cappelen Damm, 2008.

Stahl, G. (2006). Group cognition: Computer support for collaborative knowledge building. Cambridge, MA: MIT Press.

Raspberry Pi Foundation (2017). What is Raspberry Pi. http://www.raspberrypi.org/. Vygotsky, L.S. (1978). Mind in Society: The Development of Higher Psychological Processes. Cambridge, MA: Harvard University Press. 